\title{
Happy birthday Hydrobiologia! 70 years young and still growing...
}

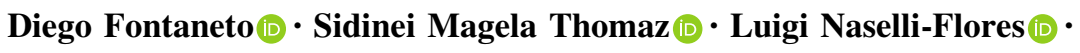 \\ Koen Martens
}

Published online: 11 January 2018

(C) Springer International Publishing AG, part of Springer Nature 2017

Hydrobiologia started its existence in March 1948 by publishing a first volume of 476 pages, and already then focused on the biology and ecology of aquatic organisms. After 70 years, the focus of the journal is still similar, but the diversity of approaches increased during the seven decades of its existence. To celebrate the 70 years of Hydrobiologia, we here address some emerging trends in the history of publications in Hydrobiologia.

Electronic supplementary material The online version of this article (https://doi.org/10.1007/s10750-017-3476-9) contains supplementary material, which is available to authorized users.

\section{Fontaneto $(\square)$}

National Research Council of Italy, Institute of Ecosystem Study, Largo Tonolli 50, 28922 Verbania Pallanza, Italy e-mail: diego.fontaneto@cnr.it

\section{S. M. Thomaz}

Universidade Estadual de Maringá, DBI/PEA/Nupélia, Av. Colombo 5790, Maringá, PR 87020-900, Brazil

e-mail: smthomaz@nupelia.uem.br

\section{Naselli-Flores}

Department of Biological, Chemical and Pharmaceutical Sciences and Technologies - Section of Botany and Plant Ecology, University of Palermo, Via Archirafi, 28, 90123 Palermo, Italy

e-mail: luigi.naselli@unipa.it
The first difference between the recent volumes and the first ones is the language: papers written in English, French, German, and Italian were all present in the first volumes, whereas only papers in English are considered now. It is emblematic that one of the most influential ecologists ever, Ramón Margalef, published two papers in the first volume of Hydrobiologia, one in French and the other one in English (Margalef, 1948a, b). The original diversity of languages reflected also the geographic diversity of the published articles, with papers reporting on studies from Africa, Asia, Europe, North America, and Oceania. Regarding this, there are no changes at all:

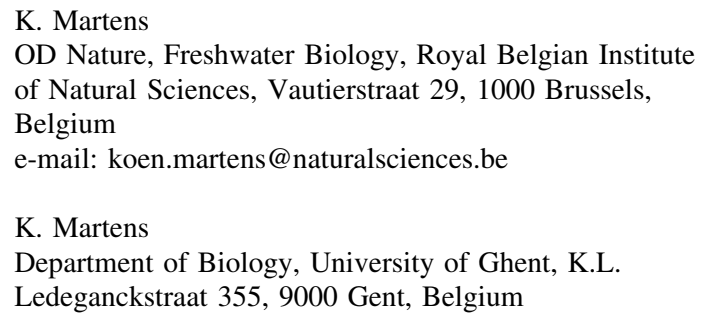


Hydrobiologia continues to publish studies from all corners of the world, and its cosmopolitan approach is visible also in the composition of the Editorial Board, which is composed of editors from almost all continents.

If we focus on the 10 most cited papers (searched through Google Scholar in November 2017; Supplementary Table S1) for each 5-year interval from 1948 to 2017, a clear trend is visible in the average number of authors per paper: from the original average of 1.1 authors per paper, the number almost constantly increased to 5.3 during the last 5-year period (Fig. 1; Mann-Kendall trend test: $z=3.9, P<0.0001)$. Thus, even if language is now limited to English, the number of collaborative works increased, without limiting the geographic coverage of the studies.

Overall, diversity and heterogeneity in all their aspects are still at the core of what Hydrobiologia strives to publish. Hydrobiologia is devoted to publishing papers that clearly address questions and hypotheses on biological diversity in aquatic habitats. Biodiversity can be loosely defined as biological diversity at the genetic, species, and community levels. As such, it has a rather vague definition, but the term became popular among lay men and in scientific literature since the end of the last century, and it is generally accepted that the first use of the term appeared in the title of a 1988 book, edited by $\mathrm{E}$.

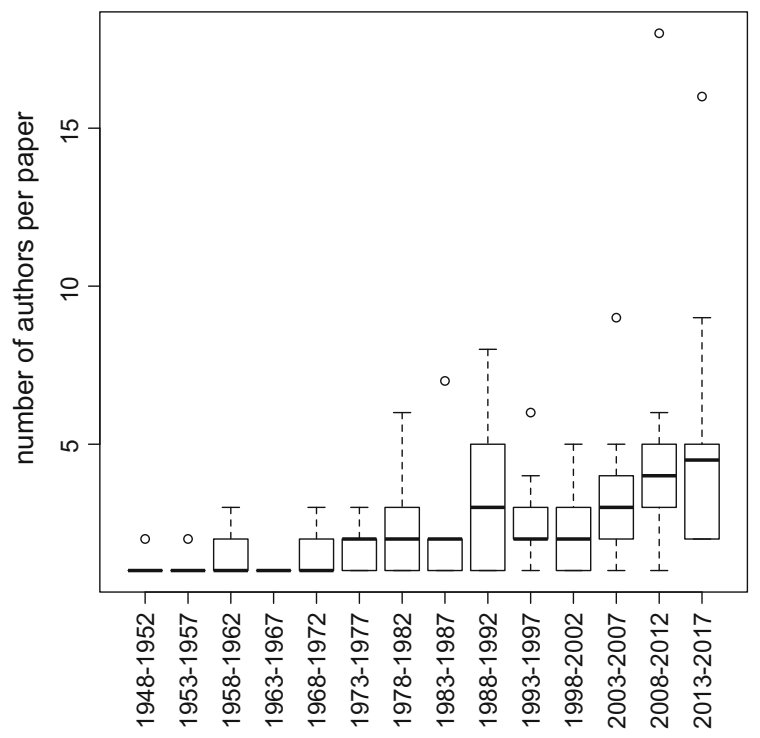

Fig. 1 Boxplot of the distribution of the number of authors per paper in Hydrobiologia in the 10 most cited papers for each quinquennium from 1948 to 2017
O. Wilson as the proceedings of a discussion forum on biological diversity held in Washington D.C. in 1986 (Wilson, 1988).

Knowledge on and understanding of the measurements, distribution, and determinants of biological diversity are pivotal to analyse current scientific issues such as ecosystem services, nature-based solutions and other societal challenges related to the environment. The study of biodiversity is potentially as old as human history: people always had to identify living organisms around them, to be able to use them and to prevent any harm from them. Even the oldest known prehistoric paintings in the Chauvet Cave (Ardèche, France) demonstrate a highly detailed and accurate knowledge on species diversity (Chauvet et al., 1996). Edward Wilson even coined a term to define the innate tendency humans have to be connected with nature: "biophilia" (Wilson, 1986). Notwithstanding such a long history in the study of biodiversity, a lot of work still needs to be done to describe the patterns and to understand the processes that lead to the origin and the maintenance of biodiversity. For example, we are still far away from having named all extant species, and potential estimates differ in orders of magnitude: up to $10^{12}$ species just among microbes (Locey \& Lennon, 2016), although we thus far only described and classified less than 2 million species. Even for the species that we assume to be well-known, we cannot completely assess their population dynamics and their distributional ranges. Moreover, we can only grasp the effects of their interactions in the communities and of how small perturbations at the individual, population, or species level could affect entire ecosystems (Hortal et al., 2015).

If we look at the same 10 most cited papers for each quinquennium we mentioned earlier (Supplementary Table S1) and we identify the ones that clearly focus on biodiversity, no significant trend appears in their abundance across the history of Hydrobiologia (Fig. 2; Mann-Kendall trend test: $z=0.9, P=$ 0.369 ), even if the highest proportion, from 0.6 to 0.7 , is in the last decade. The two most recent celebratory volumes, number 750 and 800 , dedicated to 'Emerging trends in aquatic ecology' (Martens, 2015; Naselli-Flores et al., 2017), had a comparable proportion of papers mainly addressing biodiversity issues, respectively 10/14 $(\sim 0.7)$ and 8/14 $(\sim 0.6)$, well within the range of the last decade. Thus, Hydrobiologia published studies dealing with 


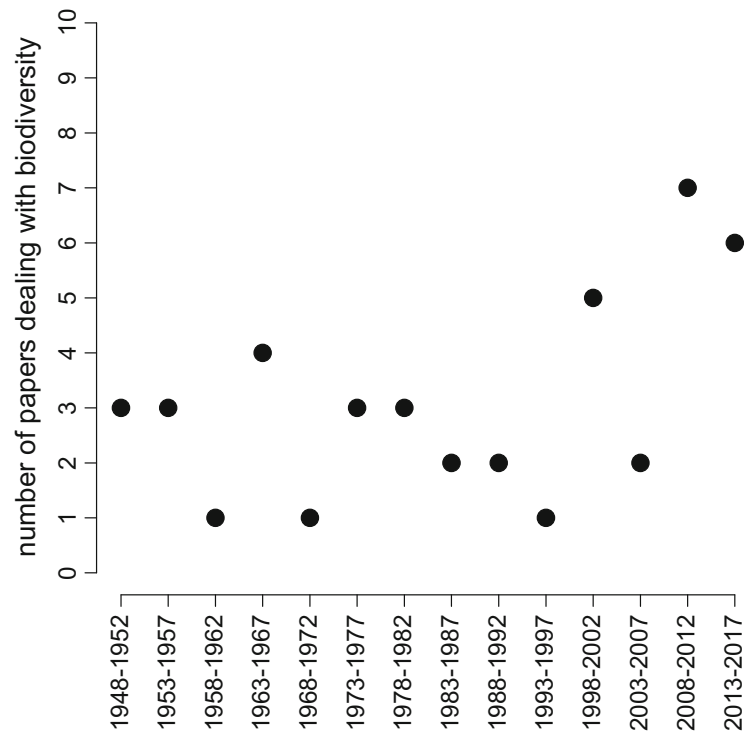

Fig. 2 Number of papers clearly dealing with biodiversity among the 10 most cited papers published in Hydrobiologia for each quinquennium from 1948 to 2017

biodiversity even before the notion of the term appeared 40 years ago, and the journal carries on doing so during the biodiversity crisis we are currently experiencing.

In this respect, it is worth mentioning the Special Issue on the "Freshwater Animal Diversity Assessment" (Balian et al., 2008), which compiled, maybe for the first time, an overview of animal biodiversity in the continental aquatic ecosystems of the world at the species and genus levels. The 62 papers published in this Special Issue have had a great scientific impact, as we can infer from their citations (12 papers were cited more than 100 times by November 2017, and kept on being regularly cited through almost 10 years, according to the Web of Science Core Collection).

Hydrobiologia is 70 years old, but it is young and vibrant, and it continuously changes to adapt (Martens, 2008). All editors of Hydrobiologia will continue to provide an outlet for the publication of high level research on the biology of aquatic organisms, without any geographic limitation, and with an open mind to the contents, the styles, and the methodologies. Moreover, the diversity of approaches and topics that can be addressed and published in our journal will ensure that Hydrobiologia will continue to publish interesting and relevant studies, anticipating both the concerns and the solutions for the future of aquatic life in our rapidly changing world.

\section{References}

Balian, E. V., H. Segers, C. Lévêque \& K. Martens, 2008. An introduction to the Freshwater Animal Diversity Assessment (FADA) project. Hydrobiologia 595: 3-8.

Chauvet, J. M., E. Brunel Deschamps \& C. Hillaire, 1996. Dawn of art: the Chauvet Cave. The Oldest Known Paintings in the World. Harry N. Abrams, Inc., New York.

Hortal, J., F. de Bello, J. A. F. Diniz-Filho, T. M. Lewinsohn, J. M. Lobo \& R. J. Ladle, 2015. Seven shortfalls that beset large-scale knowledge of biodiversity. Annual Review of Ecology, Evolution, and Systematics 46: 523-549.

Locey, K. J. \& J. T. Lennon, 2016. Scaling laws predict global microbial diversity. Proceedings of the National Academy of Sciences of the United States of America (PNAS) 113: 5970-5975.

Margalef, R., 1948a. Le phytoplancton estival de la "Costa Brava" catalene en 1946. Hydrobiologia 1: 15-21.

Margalef, R., 1948b. A new limnological method for the investigation of thin-layered epilithic communities. Hydrobiologia 1: 215-216.

Martens, K., 2008. Editorial: the future of scientific publishing. Hydrobiologia 600: 1-2.

Martens, K., 2015. Preface: emerging trends in aquatic ecology. Hydrobiologia 750: 1-4.

Naselli-Flores, L., K. Martens, D. Fontaneto \& S. M. Thomaz, 2017. Preface: emerging trends in aquatic ecology II. Hydrobiologia 800: 1-5.

Wilson, E. O., 1986. Biophilia. Harvard University Press, Cambridge.

Wilson, E. O., 1988. Biodiversity. National Academy Press, Washington, D.C. 